\title{
Efficacy of esmolol as a myocardial protective agent during continuous retrograde blood cardioplegia
}

\author{
Marcio Scorsin, MD, PhD, Alexandre Mebazaa, MD, PhD, Nawwar Al Attar, FRCS, Betta Medini, MD, \\ Jacques Callebert, PhD, Richard Raffoul, MD, Ramzi Ramadan, MD, Jean Michel Maillet, MD, Alain Ruffenach, MD, \\ François Simoneau, MD, Patrick Nataf, MD, Didier Payen, MD, PhD, and Arrigo Lessana, MD
}

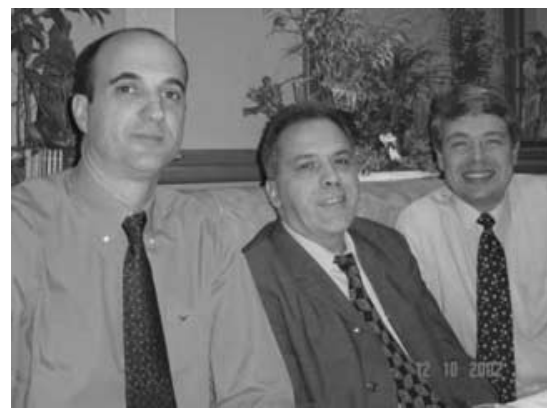

Scorsin, Lessana, Mebazaa (left to right)
From the Service de Chirurgie Cardiaque, Centre Cardiologique du Nord, Saint-Denis, France; Département d'Anesthésie-Réanimation, Service de Biochimie et de Biologie Moléculaire, CR Claude Bernard "Pathologie Expérimentale et Communications Cellulaires," Institut Fédératif de Recherche, Hôpital Lariboisière, Paris, France.

Read at the Eighty-second Annual Meeting of The American Association for Thoracic Surgery, Washington, DC, May 5-8, 2002.

Received for publication May 29, 2002; revisions requested July 8, 2002; revisions received July 22, 2002; accepted for publication Aug 14, 2002.

Address for reprints: Alexandre Mebazaa, MD, PhD (E-mail: alexandre.mebazaa@ lrb.ap-hop-paris.fr) or Marcio Scorsin, MD, PhD (E-mail: mscorsin@ hotmail.com), Département d'Anesthésie-RéanimationSMUR, Hôpital Lariboisière, 2 rue Ambroise-Paré, 75475 Paris Cedex 10, France.

J Thorac Cardiovasc Surg 2003;125:1022-9

Copyright $\odot 2003$ by The American Association for Thoracic Surgery

0022-5223/2003\$30.00+0

doi: $10.1067 / \mathrm{mtc} .2003 .175$
Objective: Esmolol, an ultra-short-acting $\beta$-blocker, is known to attenuate myocardial ischemia-reperfusion injury. The aim of this study was to compare the effects of esmolol and potassium on myocardial metabolism during continuous normothermic retrograde blood cardioplegia.

Methods: Forty-one patients operated on for isolated aortic valve stenosis were randomly assigned to continuous coronary infusion with either potassium or esmolol during cardiopulmonary bypass. Myocardial metabolism was assessed by measuring the transmyocardial gradient of oxygen content indexed to left ventricular mass of glucose, lactate, and nitric oxide. To do so, blood samples were simultaneously withdrawn upstream (in the cardioplegia line) and downstream of the myocardium (in the left coronary ostium) 10 and 30 minutes after aortic crossclamping.

Results: Although the cardioplegia flow rate and pressure were similar, esmolol markedly reduced the transmyocardial gradient of oxygen content indexed to left ventricular mass compared with potassium: $13 \pm 6$ vs $20 \pm 6 \mathrm{~mL}$ of oxygen per liter of blood per $100 \mathrm{~g}$ of myocardium, respectively, at 10 minutes and $16 \pm 8 \mathrm{vs} 24 \pm$ $8 \mathrm{~mL}$ of oxygen per liter of blood per $100 \mathrm{~g}$ of myocardium, respectively, at 30 minutes $(P=.009)$. Coronary glucose and lactate transmyocardial gradients were similar in both groups, indicating adequate myocardial perfusion in all patients at all times. In addition, during retrograde cardioplegia, esmolol showed a lower nitric oxide release compared with that caused by potassium $\left(39 \pm 49 \mu \mathrm{mol} \times \mathrm{L}^{-1}\right.$ for potassium vs $14 \pm 8 \mu \mathrm{mol} \times \mathrm{L}^{-1}$ for esmolol at 10 minutes and $39 \pm 47 \mu \mathrm{mol} \times$ $\mathrm{L}^{-1}$ for potassium vs $6 \pm 8 \mu \mathrm{mol} \times \mathrm{L}^{-1}$ for esmolol at 30 minutes, $P=.05$ ). However, hemodynamic parameters and plasma troponin I levels remained unchanged postoperatively between the 2 types of cardioplegia.

Conclusion: Esmolol provides potent myocardial protection in hypertrophied hearts, at least in part, by reducing myocardial oxygen metabolism.

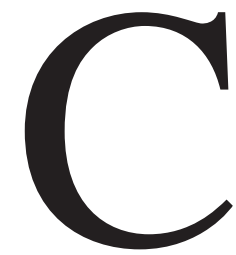
ardioplegia-induced cardiac arrest is routinely used to provide myocardial protection, as well as a flaccid heart, during cardiac operations. This is mostly achieved by using hyperkalemic cardioplegia solution ${ }^{1,2}$; however, hyperkalemia has many adverse effects. ${ }^{3-5}$ Patients who cannot eliminate the large amount of potassium administered during cardiopulmonary bypass (CPB) might present a persistent increase of myocardial intracellular calcium concentration that might ultimately impair contraction-relaxation of cardiac cells, ${ }^{5}$ induce longer periods of bypass, and require pharmacologic or mechanical inotropic support. Animal and human ${ }^{6,7}$ studies suggest that, as an alternative approach to hyperkalemic cardioplegic arrest, myocardial protection can be achieved with the use of the ultra-short-acting $\beta$-receptor blocker esmolol. ${ }^{8-10}$ Indeed, $\beta$-receptor blockers might reduce the extent of myocardial cell injury ${ }^{11-13}$ and reduce myocardial oxygen 
consumption by means of better oxygen use. ${ }^{14,15}$ The latter, however, might be overcome by the persistence of a minimal myocardial contraction when using esmolol during aortic crossclamping.

Thus, the main objective of this study was to assess, in patients operated on for aortic valve replacement with hypertrophied left ventricles, whether esmolol can be as efficient as potassium in protecting the myocardium during continuous retrograde blood cardioplegia. Myocardial hypertrophy was chosen because of its widely known decreased tolerance to ischemia during cardiac surgery. To do so, we compared effects of esmolol and potassium on preoperative and postoperative hemodynamic and biologic parameters and on myocardial metabolic function, including myocardial oxygen, glucose, and lactate use and myocardial nitric oxide (NO) production during the aortic crossclamping period.

\section{Methods}

\section{Patients}

Forty-three patients with isolated aortic stenosis free from significant coronary artery lesions and scheduled for elective surgery were admitted into the study. The study was approved by the Ethics Committee of Hôpital Saint-Louis (Paris, France), and written informed consent was obtained from each patient in the preoperative period after a detailed explanation of the study's purpose by one of the investigators. Patients were randomly assigned to receive either the cardioselective $\beta$-receptor blocker esmolol (half-life of 9 minutes ${ }^{16}$; Baxter International, Inc, Deerfield, Ill) or potassium during aortic crossclamping. Prerandomization exclusion criteria were preoperative $\beta$-blocker treatment and a history of severe asthma. After randomization, 2 patients from the potassium group were excluded because the coronary sinus could not be cannulated for retroperfusion. Thus, 23 patients were assigned to the esmolol group, and 18 patients were assigned to the potassium group. Preoperative patient data are shown in Table 1.

\section{Operative Technique for Continuous Retrograde Blood Cardioplegia}

All patients were operated on for isolated aortic valve replacement through a median sternotomy, and CPB was set up according to the standard procedure between the ascending aorta for arterial inflow and in the right atrium by using a 2-stage cannula for venous return. A vent was placed in the left ventricular (LV) cavity through the right superior pulmonary vein. $\mathrm{CPB}$ was conducted during normothermia (perfusion temperature was maintained at $37^{\circ} \mathrm{C}$ ), with a theoretical flow of $2.5 \mathrm{~L} \times \mathrm{min}^{-1} \times \mathrm{m}^{-2}$

In addition to aortic crossclamping, initial antegrade flow of cardioplegic solution was started in the aortic root through a line originating from the arterial part of the oxygenator, with potassium or esmolol diluted in normoxic blood (oxygen saturation of $>97 \%$, with $\mathrm{PaO}_{2}$ ranging from 90-120 mm Hg and blood flow of $0.3 \mathrm{~L} \times$ $\left.\min ^{-1}\right)$. Potassium $\left(0.2 \mathrm{~g} \times \mathrm{mL}^{-1}\right)$ was administered at a total dose of approximatively $1.2 \mathrm{~g}$ in the potassium group, whereas esmolol $\left(50 \mathrm{mg} \times \mathrm{mL}^{-1}\right)$ was administered at a total dose of 250
TABLE 1. Comparison of preoperative and intraoperative parameters

K group

ES group

Preoperative parameters

Age (y)

$\mathrm{LV}$ mass index $\left(\mathrm{g} \cdot \mathrm{m}^{-2}\right)$

Preoperative LVEF (\%)

Transaortic mean gradient* $(\mathrm{mm} \mathrm{Hg})$

Preoperative $\mathrm{Hb}(\mathrm{g} / \mathrm{dL})$

Intraoperative parameters

Aortic crossclamping time (min)

CPB time (min)

$\begin{array}{rr}68 \pm 11 & 70 \pm 11 \\ 197 \pm 57 & 176 \pm 48 \\ 59 \pm 13 & 65 \pm 12 \\ 58 \pm 12 & 56 \pm 13 \\ 13.6 \pm 2.2 & 13.2 \pm 1.6 \\ 58 \pm 10 & 54 \pm 11 \\ 79 \pm 9 & 80 \pm 13\end{array}$

No difference was observed between the 2 groups. $K$, Potassium; $E S$, esmolol; LV mass index, LV mass/body surface area; LVEF, LV ejection fraction; $H b$, hemoglobin.

*Determined by means of 2-dimensional echocardiography.

to $300 \mathrm{mg}$ in the esmolol group, both administered over 2 to 3 minutes in the cardioplega line. Although the heart was consistently arrested in the potassium group without apparent contraction, it remained beating in the esmolol group at a rate of less than 30 beats/min with minimal myocardial contraction during aortic crossclamping. For clarity, we will, however, use the term "cardioplegia" for both agents. After induction of cardioplegia in the potassium group or minimal myocardial contraction in the esmolol group (consistently $<3$ minutes for both solutions), antegrade perfusion was stopped and relayed by means of retrograde continuous myocardial perfusion through a self-inflating double-lumen balloon cannula (DLP, Grand Rapids, Mich) placed by means of a transright atrial blind cannulation of the coronary sinus. The myocardial perfusion flow rate was kept constant at approximately 0.25 $\mathrm{L} \times \min ^{-1}$ to maintain a coronary sinus pressure of between 30 and $40 \mathrm{~mm} \mathrm{Hg}$. Cardioplegia was therefore maintained with a dose of 4 to $6 \mathrm{~g} \times \mathrm{h}^{-1}$ of potassium to obtain a final potassium concentration of $12 \mathrm{mmol} \times \mathrm{L}^{-1}$ in the cardioplegia line in the potassium group. Minimal myocardial contraction in the esmolol group was maintained with a dose of $600 \mathrm{mg} \times \mathrm{h}^{-1}$, which was reduced to 300 to $400 \mathrm{mg} \times \mathrm{h}^{-1}$ if the heart rate decreased to less than 30 beats $/ \mathrm{min}$. Magnesium was also administered to all patients at a dose of $125 \mathrm{~mL} \times \mathrm{h}^{-1}$ of $10 \% \mathrm{MgSO}_{4}$.

\section{Measurements}

Hemodynamic parameters. Transesophageal echocardiography was performed 1 day before and 5 days after the surgical procedure to assess LV ejection fraction. Penn-cube LV mass was measured, as previously described ${ }^{17}$ :

$$
1.04\left([\text { IVST + LVID + PWT }]^{3}-\text { LVID) }\right)^{3}-13.6 \mathrm{~g}
$$

where IVST is defined as interventricular septal thickness, LVID is defined as LV internal dimension, and PWT is defined as posterior wall thickness. All values are measured during end-diastole, and the results were then indexed to body surface area. After obtainment of general anesthesia and tracheal intubation, a Swan-Ganz catheter (Edwards Lifesciences, Irvine, Calif) was introduced into the pulmonary artery to record baseline hemodynamics before sternotomy: mean pulmonary arterial pressure, cardiac index, and mixed pulmonary artery oxygen saturation. Data were also re- 
TABLE 2. Comparison of myocardial metabolic data and parameters measured in the retrograde perfusion line between the potassium and esmolol groups during retrograde cardioplegia

\begin{tabular}{lccccc}
\hline & \multicolumn{2}{c}{ ACC + 10 min } & & \multicolumn{2}{c}{ ACC + 30 min } \\
\cline { 2 - 3 } \cline { 5 - 6 } & K group & ES group & & K group & ES group \\
\hline Cardioplegic roller-pump flow rate $\left(\mathrm{L} \cdot \mathrm{min}^{-1}\right)$ & $0.26 \pm 0.03$ & $0.25 \pm 0.03$ & & $0.27 \pm 0.03$ & $0.26 \pm 0.03$ \\
Cardioplegic oxygen content $\left(\mathrm{mL} \mathrm{of} \mathrm{oxygen} \cdot \mathrm{L}^{-1}\right)$ & $120 \pm 28$ & $120 \pm 25$ & & $129 \pm 22$ & $118 \pm 25$ \\
Cardioplegic glucose content $\left(\mathrm{mmol} \cdot \mathrm{L}^{-1}\right)$ & $6.6 \pm 1.7$ & $6.5 \pm 1.1$ & & $7.2 \pm 1.0$ & $6.7 \pm 1.2$ \\
Transmyocardial glucose gradient $\left(\mathrm{mmol} \cdot \mathrm{L}^{-1}\right)$ & $0.4 \pm 0.2$ & $0.6 \pm 0.6$ & & $0.5 \pm 0.3$ & $0.3 \pm 0.2$ \\
Cardioplegic lactate content $\left(\mathrm{mmol} \cdot \mathrm{L}^{-1}\right)$ & $1.45 \pm 0.37$ & $1.67 \pm 0.55$ & & $1.55 \pm 0.35$ & $1.69 \pm 0.53$ \\
Transmyocardial lactate gradient $\left(\mathrm{mmol} \cdot \mathrm{L}^{-1}\right)$ & $0.17 \pm 0.22$ & $0.16 \pm 0.25$ & & $0.16 \pm 0.27$ & $0.22 \pm 0.30$ \\
\hline
\end{tabular}

Measurements were performed 10 and 30 minutes after aortic crossclamping. $\mathrm{TMO}_{2}$ is shown in Figure 1 . $K$, Potassium; ES, esmolol; $A C C$, aortic crossclamping.

corded 4 hours after the end of the operation. All measurements were made at a fraction of inspired oxygen of 0.5 . The need for catecholamines after $\mathrm{CPB}$ was also recorded.

Metabolic parameters. Blood samples were taken to measure plasma lactate, troponin I, and creatinine levels before sternotomy and at 4 hours after the operation. The plasma troponin I level was also measured 24 hours after the operation. Furthermore, other blood samples were taken during CPB to assess the transmyocardial gradient of oxygen content indexed to body surface area ( $\mathrm{TMO}_{2}$; see calculations below), and the transmyocardial gradient of plasma glucose, lactate (to assess whether myocardial blood perfusion was adequate), and nitrate $\left(\mathrm{NO}_{2} / \mathrm{NO}_{3}\right.$, index of myocardial NO production). To do so, blood samples were simultaneously withdrawn upstream in the cardioplegia line and downstream of the myocardium in the left coronary ostium through a coronary balloon-tipped, angled soft cannula (Polystan A/S, Vaerløse, Denmark) to avoid any possible contamination with blood from the left ventricle. Blood samples were withdrawn 10 and 30 minutes after aortic crossclamping. Plasma nitrite and nitrate levels were measured by using the Griess method, as previously described. ${ }^{18}$ In brief, nitrate present in the sample was reduced on nitrite by the enzyme nitrate reductase, and the total nitrite formed is measured on the basis of its absorbance at $550 \mathrm{~nm}$.

\section{Continuous Antegrade Blood Cardioplegia}

To assess whether differences in transmyocardial oxygen content and NO release between the esmolol and potassium groups could be related to the direction of cardioplegic blood flow rather than to a cardioplegic agent, we measured these parameters in 10 additional patients receiving cardioplegic solution through the antegrade route (potassium group, $\mathrm{n}=5$; esmolol group, $\mathrm{n}=5$ ). In brief, after induction of cardiac arrest, the aorta was opened, and the left and right coronary ostia were cannulated and continuously perfused through 2 coronary balloon-tipped, angled soft cannulas at a flow rate of $0.2 \mathrm{~L} \times \mathrm{min}^{-1}$. Doses of potassium and esmolol were identical to and had the same effects as those described above for retrograde perfusion. Measurements (oxygen content and NO concentration) were performed 10 and 30 minutes after aortic crossclamping in both the cardioplegia line and the self-inflating double-lumen balloon cannula inserted in the coronary sinus. Indeed, during antegrade cardioplegia, blood from the coronary sinus was considered downstream of the myocardium.

\section{Calculations}

The transmyocardial gradient for retrograde perfusion is defined as follows: Plasma concentration (or oxygen content) in the perfusion line - Plasma concentration (or oxygen content) in the left coronary ostium.

The transmyocardial gradient for antegrade perfusion is defined as follows: Plasma concentration (or oxygen content) in the perfusion line - Plasma concentration (or oxygen content) in the coronary sinus.

Oxygen content is defined as follows: $1.39 \times$ Oxygen saturation $\times$ Hemoglobin concentration $+0.0031 \times$ Blood oxygen pressure.

\section{Statistics}

Data are presented as means $\pm \mathrm{SD}$. Comparisons were performed by using the unpaired Student $t$ test or 2-way analysis of variance for one grouping factor (potassium vs esmolol) and one within factor (time) when appropriate.

\section{Results}

Our study included patients with severe aortic stenosis with a high LV mass index and a high transaortic mean gradient (Table 1). Preoperative measurements and aortic crossclamping and CPB times were similar in the esmolol and potassium groups.

Table 2 shows that parameters measured in the retrograde perfusion line, namely oxygen content, plasma glucose concentration, and lactate concentration, were similar in the potassium and esmolol groups at 10 and 30 minutes after aortic crossclamping. Figure 1 shows that $\mathrm{TMO}_{2}$ was lower in the esmolol group than in the potassium group during the entire observational period and that $\mathrm{TMO}_{2}$ increased in all patients, regardless of the cardioplegic agent used, during aortic crossclamping $(P<.001)$. However, the transmyocardial gradients of lactate and glucose were unchanged and in the low physiologic levels in both groups (Table 2). Accordingly, our data show that myocardial oxygen consumption was consistently less in the esmolol than in the potassium group, with no signs of inadequate oxygen use. 

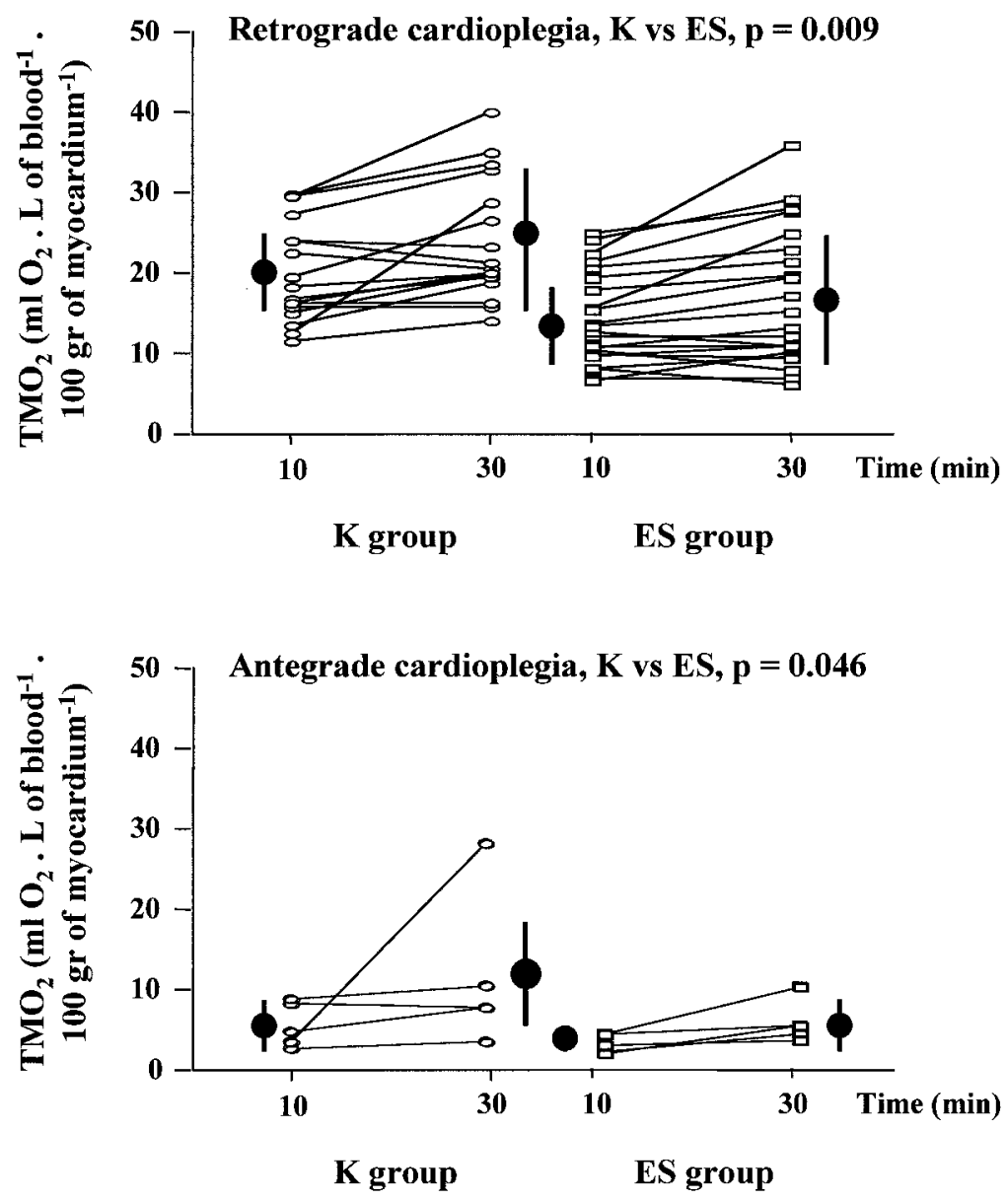

Figure 1. Individual data of transmyocardial oxygen content indexed to $\mathrm{LV}$ mass $\left(\mathrm{TMO}_{2}\right)$ in the potassium $(\mathrm{K})$ and esmolol (ES) groups during retrograde (potassium group, $n=18$; esmolol group, $n=23$ ) or antegrade (potassium group, $n=5$; esmolol group, $n=5$ ) coronary perfusion. These measurements were repeated 10 and 30 minutes after aortic crossclamping. In addition, an increase in transmyocardial oxygen content indexed to LV mass was observed during aortic crossclamping in all patients regardless of the cardioplegic agent used or the direction of cardioplegic blood perfusion $(P<.001)$.

Our study further compared the transmyocardial gradient of NO release during aortic crossclamping time between the potassium group $(n=10)$ and the esmolol group $(n=8)$ during retrograde cardioplegia. Figure 2 shows that transmyocardial gradient of NO release decreased in the esmolol group during aortic crossclamping, whereas it remained stable in the potassium group.

$\mathrm{TMO}_{2}$ and transmyocardial NO release were also measured in 10 additional patients (potassium group, $\mathrm{n}=5$; esmolol group, $\mathrm{n}=5$ ) during continuous normothermic antegrade cardioplegia. Figure 1 shows that the $\mathrm{TMO}_{2}$ was much lower in antegrade cardioplegia in all patients than in retrograde cardioplegia and that the $\mathrm{TMO}_{2}$ remained lower in the esmolol group than in the potassium group during antegrade cardioplegia compared with during retrograde cardioplegia. Surprisingly, we found a much lower transmyocardial gradient of NO release in all 10 patients in antegrade compared with retrograde cardioplegia, with no difference between the potassium and esmolol groups (Figure 2). The transmyocardial gradient of glucose (esmolol group, $0.3 \pm 0.1 \mathrm{mmol} \times \mathrm{L}^{-1}$; potassium group, $0.6 \pm 0.5$ mmol $\times \mathrm{L}^{-1}$; both after 30 minutes of aortic crossclamping) and lactate (esmolol group, $0.10 \pm 0.24 \mathrm{mmol} \times \mathrm{L}^{-1}$; potassium group $0.35 \pm 0.94 \mathrm{mmol} \times \mathrm{L}^{-1}$; both after 30 minutes of aortic crossclamping) were unaltered by antegrade cardioplegia.

Hemodynamic and biologic parameters were recorded 4 hours after the operation and compared with those recorded preoperatively in the 41 patients who received retrograde cardioplegia (Table 3). Cardiac index, plasma troponin I level, and plasma lactate level increased in a similar manner in the postoperative period in the 2 groups $(P<.01$ for all). 


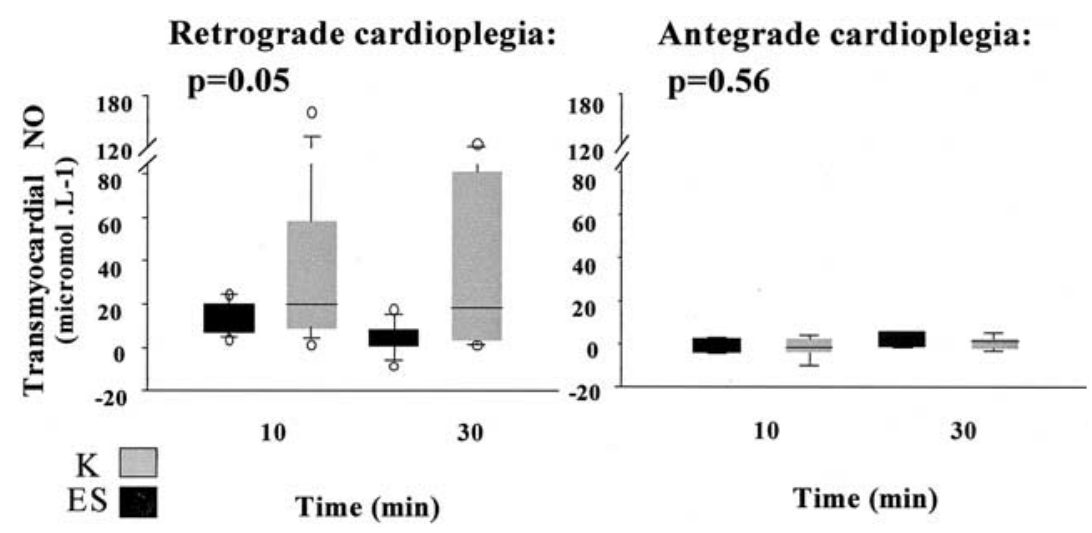

Figure 2. Comparison of transmyocardial NO release in the potassium (K) and esmolol (ES) groups during retrograde (potassium group, $n=10$; esmolol group, $n=8$ ) or antegrade (potassium group, $n=5$; esmolol group, $n=5$ ) cardioplegic perfusion. These measurements were repeated 10 and 30 minutes after aortic crossclamping. $P$ values represent differences between the potassium and esmolol groups; there was no effect of time.

TABLE 3. Comparison of hemodynamic and biologic parameters between preoperative and postoperative periods in the potassium and esmolol groups

\begin{tabular}{|c|c|c|c|c|}
\hline & \multicolumn{2}{|c|}{ Preoperative } & \multicolumn{2}{|c|}{ Postoperative (4 h) } \\
\hline & K group & ES group & K group & ES group \\
\hline Cardiac index $\left(\mathrm{L} \cdot \mathrm{min}^{-1} \cdot \mathrm{m}^{-2}\right)$ & $2.1 \pm 0.6$ & $2.3 \pm 0.8$ & $2.8 \pm 0.5^{*}$ & $2.7 \pm 0.7^{*}$ \\
\hline Mixed pulmonary artery oxygen saturation (\%) & $73 \pm 8$ & $74 \pm 7$ & $73 \pm 6$ & $72 \pm 7$ \\
\hline Mean PAP $(\mathrm{mm} \mathrm{Hg})$ & $27 \pm 9$ & $23 \pm 6$ & $25 \pm 7$ & $24 \pm 5$ \\
\hline Troponin I $\left(\mu \mathrm{g} \cdot \mathrm{L}^{-1}\right)$ & $0.0 \pm 0.0$ & $0.2 \pm 0.5$ & $4.7 \pm 2.7^{*}$ & $4.8 \pm 2.3^{*}$ \\
\hline Lactate $\left(\mathrm{mmol} \cdot \mathrm{L}^{-1}\right)$ & $1.1 \pm 0.5$ & $1.4 \pm 0.4$ & $1.9 \pm 1.1^{*}$ & $2.5 \pm 1.6^{*}$ \\
\hline Creatinine $\left(\mu \mathrm{mol} \cdot \mathrm{L}^{-1}\right)$ & $88 \pm 18$ & $95 \pm 33$ & $94 \pm 28$ & $94 \pm 28$ \\
\hline
\end{tabular}

Troponin and lactate represent plasma concentrations. No difference was found between the $\mathrm{K}$ and ES groups for any measured parameter. $K$, Potassium; $E S$, esmolol; $P A P$, pulmonary arterial pressure.

${ }^{*} P<.01$ versus the same group at the preoperative period.

A similar number of patients received catecholamines, mostly dobutamine, in the post-CPB period in both groups (esmolol group, 7/23; potassium group, 8/18). In addition, plasma troponin I levels at 24 hours after the operation (potassium group, $4.7 \pm 2.9 \mu \mathrm{g} \times \mathrm{L}^{-1}$; esmolol group, $6.4 \pm 3.0 \mu \mathrm{g} \times \mathrm{L}^{-1}$ ), ventilation time (esmolol group, $13 \pm$ 17 hours [median, 6 hours]; potassium group, $9 \pm 5$ hours [median, 7 hours]) and length of stay in the intensive care unit (esmolol group, $3.3 \pm 1.8$ days; potassium group, $3.5 \pm$ 1.7 days) were similar in both groups. LV ejection fraction measured by means of echocardiography 5 days after the operation was also similar in the esmolol and potassium groups $(59 \% \pm 19 \%$ and $62 \% \pm 11 \%$, respectively) and unchanged compared with preoperative values. The mortality rate was $0 \%$ at 3 months.

\section{Discussion}

Esmolol has been described as an effective cardioprotective agent in a few human studies, mostly involving patients operated on for coronary bypass surgery. ${ }^{6,7}$ Thus, continu- ous coronary perfusion with warm esmolol-enriched blood has been shown to minimize anaerobic metabolism and myocardial edema formation. We also showed, in the present study, that esmolol could be an effective cardioprotective agent in hypertrophied human ventricles despite a high myocardial oxygen consumption ${ }^{19}$ and an altered delivery of oxygen and other energy substrates to cardiac myocytes, mostly because of reduced capillary density, increased collagen content, or both. ${ }^{20}$ In addition, although continuous retrograde blood cardioplegia has been claimed to provide sufficient oxygen and energy substrates for aerobic myocardial metabolism, ${ }^{21}$ its protective abilities are still debated.22 Our data strongly suggest that the combination of esmolol and continuous retrograde blood cardioplegia offers an optimal cardioprotective method for aortic valve replacement.

Our study showed that esmolol administered during aortic crossclamping markedly reduced $\mathrm{TMO}_{2}$ compared with potassium in all patients, regardless of the direction (antegrade or retrograde) of myocardial perfusion flow. This 
implies that myocardial oxygen consumption $\left(\mathrm{TMO}_{2} \times\right.$ cardioplegia blood flow) was lower with esmolol than with potassium. This was unexpected. Indeed, because heart contractile activity accounts for $70 \%$ to $80 \%$ of myocardial oxygen consumption, ${ }^{23}$ we expected that heart contraction in the esmolol group, although minimal, would have increased myocardial oxygen consumption to a greater level than that of the unbeating heart in the potassium group. Our data also showed that esmolol-induced low myocardial oxygen consumption was not related to oxygen misconsumption because neither the transmyocardial gradient of lactate nor that of glucose was altered in the esmolol group compared with that in the potassium group at any time. This was confirmed by similar levels of the global marker of myocardial ischemia, plasma troponine I, in both groups at all measured times. Mechanism of the difference in myocardial oxygen consumption between the esmolol and potassium groups remains to be elucidated. Indeed, hyperkalemic cardioplegic solutions induce a depolarization of membrane resting potential and an inactivation of fast $\mathrm{Na}^{+}$channels that result in diastolic cardiac arrest. ${ }^{24}$ However, it also causes $\mathrm{Ca}^{2+}$ influx into cardiac myocyte and cardiac endothelial cells, ${ }^{25}$ which results in increasing myocardial oxygen consumption. By contrast, esmolol, as with other $\beta$-blockers, is known to decrease myocardial oxygen consumption and ultimately to improve oxygen use in human patients. ${ }^{8,15}$

Our study also showed a lower $\mathrm{TMO}_{2}$ in continuous antegrade cardioplegia compared with that in continuous retrograde blood cardioplegia. This difference is likely explained by the different percentage of nutritive flow delivered to the myocardium with these 2 techniques. Indeed, although the nutritive flow to the myocardium per se is almost $100 \%$ of the cardioplegic perfusion in continuous antegrade cardioplegia, it ranges from $30 \%$ to $70 \%$ in continuous retrograde cardioplegia. ${ }^{26,27}$ In the latter, cardioplegic perfusion is partly bypassing the myocardial capillary bed, going directly to the right ventricular or LV cavities through the thebesian veins.

Our study also demonstrated an important transmyocardial gradient of NO release a couple of minutes after the shift of cardioplegia flow direction from antegrade to retrograde in all patients, regardless of the cardioplegic agent used. These data favor endothelial cells as a potential source of NO release rather than cardiac myocytes. Indeed, in our study sudden changes in flow-derived mechanical stresses and the biochemical environment in coronary endothelium after the change of cardioplegic blood flow direction from antegrade to retrograde might have increased endothelial NO release, as previously described. ${ }^{28,29}$ These sudden alterations, compared with physiologic conditions, include blood flow direction at the opposite direction of the physiologic alignment of the endothelial cell layer, an increase in coronary venous pressure from a couple of millimeters of mercury in physiologic conditions to 30 to $40 \mathrm{~mm} \mathrm{Hg}$ during cardioplegia, and a sudden increase in oxygen tension in coronary veins at levels present in the arteries. Our study further showed that potassium induced a sustained NO release during aortic crossclamping, whereas NO release decreased with esmolol during retrograde cardioplegia. Indeed, a high potassium concentration is known to increase the intracellular $\mathrm{Ca}^{2+}$ concentration (see above), which might stimulate the calcium-dependent constitutive isoforms of NO synthase, especially NO synthase 3, in endothelial cells. Although the clinical relevance of the coronary perfusion-induced NO release is still uncertain, evidence shows that NO might have potential beneficial effects on ventricular relaxation, coronary circulation, or both, especially in ischemic and hypertrophied human ventricles, ${ }^{20}$ but also deleterious effects if transformed to the toxic oxidant peroxynitrite. ${ }^{30}$

In summary, our study showed that esmolol can be safely used as a continuous retrograde protective agent in the hypertrophied human heart. Furthermore, esmolol markedly decreased myocardial oxygen consumption compared with potassium, with no signs of myocardial insult. In addition, our study showed a much greater NO production with retrograde than antegrade cardioplegia, regardless of the agent used.

We thank Professor Eric Vicaut (Centre d'Investigations Clinique, UFR Lariboisière-Saint Louis) for his statistical advice and Isabelle Perche for her continuous support.

\section{References}

1. Gay W. Crystalloid potassium cardioplegia: concepts and early studies. Ann Thorac Surg. 1994;58:1285-6.

2. Tyers G, Manley N, Williams E, Schaffer C, William D, Kurusz M. Preliminary clinical experience with isotonic hypothermic potassium induced arrest. J Thorac Cardiovasc Surg. 1977;74:674-81.

3. Kupriyanov V, Xiang B, Butler K, St-Jean M, Deslauriers R. Contractile dysfunction caused by normothermic ischemia and $\mathrm{KCl}$ arrest in the isolated pig heart: a 31P NMR study. J Mol Cell Cardiol. 1995;27:1715-30

4. Handy J, Spinale F, Mukherjee R, Crawford F. Hypothermic potassium cardioplegia impairs myocyte recovery of contractility and inotropy. J Thorac Cardiovasc Surg. 1994;107:1050-8.

5. Jovanovic A, Lopez JR, Alekseev AE, Shen WK, Terzic A. Adenosine prevents $\mathrm{K}^{+}$-induced $\mathrm{Ca}^{2+}$ loading: insight into cardioprotection during cardioplegia. Ann Thorac Surg. 1998;65:586-91.

6. Kuhn-Régnier F, Natour E, Dhein S, Dapunt O, Geissler HJ, LaRose $\mathrm{K}$, et al. Beta-blockade versus Buckberg blood-cardioplegia in coronary bypass operation. Cardiovasc Surg. 1999;15:67-74.

7. Mehlhorn U, Sauer H, Kuhn-Régnier F, Südkamp M, Dhein S, Eberhardt $\mathrm{F}$, et al. Myocardial $\beta$-blockade as an alternative to cardioplegic arrest during coronary artery surgery. Cardiovasc Surg. 1999;7:54957.

8. Ede M, Ye J, Gregorash L, Summers R, Pargaonkar S, LeHouerou D, et al. Beyond hyperkalemia: $\beta$-blocker-induced cardiac arrest for normothermic cardiac operations. Ann Thorac Surg. 1997;63:721-7.

9. Bessho R, Chambers D. Myocardial protection: the efficacy of an ultra-short-acting $\beta$-blocker, esmolol, as a cardioplegic agent. $J$ Thorac Cardiovasc Surg. 2001;122:993-1003. 
10. Warters RD, Allen SJ, Davis KL, Geisser HJ, Bischoff I EM, Mutschler $\mathrm{E}$, et al. $\beta$-Blockade as an alternative to cardioplegic arrest during cardiopulmonary bypass. Ann Thorac Surg. 1998;65:961-6.

11. Geissler HJ, Davis KL, Allen SJ, Buja LM, Laine GA, Mehlhorn U, et al. High-dose $\beta$-blockade during reperfusion only reduces ischemiareperfusion injury [abstract]. FASEB J. 1998;12:A4124.

12. Laub G, Muralidharan S, Reibman J, Fernandez J, Anderson W, Gu J, et al. Esmolol and percutaneous cardiopulmonary bypass enhance myocardial salvage during ischemia in a dog model. $J$ Thorac Cardiovasc Surg. 1996;111:1085-91.

13. Kandhoudi N, Percevault-Albadine J, Bril A. Comparative effects of carvedilol and metoprolol on cardiac ischemia-reperfusion injury. J Cardiovasc Pharmacol. 1998;32:443-51.

14. Kloner RA, Kirshenbaum J, Lange R, Antman EM, Braunwald E. Experimental and clinical observations on the efficacy of esmolol in myocardial ischemia. Am J Cardiol. 1985;56:40F-8F.

15. Beanlands R, Nahmias C, Gordon E, Coastes G, deKemp R, Firnau G, et al. The effects of $\beta_{1}$-blockade on oxidative metabolism and the metabolic cost of ventricular work in patients with left ventricular dysfunction. A double-blind, placebo-controlled, positron-emission tomography study. Circulation. 2000;102:2070-5.

16. Sum CY, Yacobi A, Kartzinel R, Stampfli H, Davis CS, Lai CM Kinetics of esmolol, an ultra-short-acting $\beta$-blocker, and of its major metabolite. Clin Pharmacol Ther. 1983;34:427-34.

17. Devereux R, Alonso D, Lutas E, Gottlieb G, Campo E, Sachs Reichek N. Echocardiographic assessment of left ventricular hypertrophy: comparison to necropsy findings. Am J Cardiol. 1986;57:450-8.

18. Giovannoni G, Land J, Keir G, Thompson E, Heales S. Adaptation of nitrate reductase and Griess reaction methods for the measurement of serum nitrate plus nitrite levels. Ann Clin Biochem. 1997;34:193-8.

19. Laine H, Katoh C, Luotolahti M, Yki-Järvinen H, Kantola I, Jula A, et al. Myocardial oxygen consumption is unchanged but efficiency is reduced in patients with essential hypertension and left ventricular hypertrophy. Circulation. 1999;100:2425-30.

20. Matter C, Mandinov L, Kaufman PA, Vassali G, Jiang Z, Hess OM. Effect of $\mathrm{NO}$ donors on $\mathrm{LV}$ diastolic function in patients with severe pressure-overload hypertrophy. Circulation. 1999;99:2396-401.

21. Salerno T, Houck J, Barrozo C, Panos A, Christakis G, Abel J, et al. Retrograde continuous warm blood cardioplegia: a new concept in myocardial protection. Ann Thorac Surg. 1991;51:245-7.

22. Caputo M, Ascione R, Angelini GD, Suleiman MS, Bryan AJ. The end of cold era: from intermittent cold to intermittent warm blood cardioplegia. Eur J Cardiothorac Surg. 1998;14:467-75.

23. Buckberg G, Brazier J, Nelson R, Goldstein S, McConnel D, Cooper N. Studies of the effects of hypothermia on regional myocardial blood flow and metabolism during cardiopulmonary bypass. I. The adequately perfused beating, fibrillating, and arrested heart. $J$ Thorac Cardiovasc Surg. 1977;73:87-94.

24. Chambers DJ, Hearse DJ. Developments in cardioprotection: "polarized" arrest as an alternative to "depolarized" arrest. Ann Thorac Surg. 1999;68:1960-6.

25. Lopez JR, Ghanbari RA, Terzic A. A $\mathrm{K}_{\mathrm{ATP}}$ channel opener protects cardiomyocytes from $\mathrm{Ca}^{2+}$ waves: a laser confocal microscopy study. Heart Circ Physiol. 1996;39:1384-9.

26. Caldarone C, Krukenkamp I, Misare B, Levitsky S. Perfusion deficits with retrograde warm blood cardioplegia. Ann Thorac Surg. 1994;57: 403-6.

27. Partington M, Acar C, Buckberg G, Julia P, Kofsky E, Bugyi H Studies of retrograde cardioplegia. I. Capillary blood flow distribution to myocardium supplied by open and occluded arteries. $J$ Thorac Cardiovasc Surg. 1989;97:605-12.

28. Mebazaa A, Randall W, Cherian M, Abraham M. Comparison between endocardial and great vessel endothelial cells morphology, growth, and prostaglandin release. Am J Physiol. 1995;268:H250-9.

29. Davies P, Tripathi S. Mechanical stress mechanisms and the cell. An endothelial paradigm. Circ Res. 1993;1993:239-45.

30. Lanone S, Manivet P, Callebert J, Launay J, Payen D, Aubier M, et al Inducible nitric oxide synthase (NOS-2) expressed in septic patients is nitrated on selective tyrosine residues: implications in enzymatic activities. Biochem J. 2002;366(Pt 2):399-404.

\section{Discussion}

Dr Tomas A. Salerno (Miami, Fla). Ideal myocardial protection requires the infusion of cardioplegia, antegrade and retrograde, either alternating, as shown by Buckberg, or simultaneously, as shown by Buckberg and our group. Furthermore, Roxanne Deslauriers from our group showed that retrograde cardioplegia in pigs does not provide uniform myocardial distribution of flow. This might explain your results.

I have a couple of questions for you. First, how long was your crossclamp time, and did you refuse antegrade cardioplegia?

Second, in those hearts did you measure and did you have an opportunity to do myocardial biopsies to measure the energetics of the heart, microscopy, cellular edema, and other factors?

Your article is an important contribution. I have come all the way from eliminating potassium from cardioplegia, but I have not used esmolol.

Dr Scorsin. Thank you, Dr Salerno, for your kind remarks. Our crossclamp time was around 60 minutes.

Your second question was whether we have done biopsies or other measurements. No, we made only those measurements I showed you.

Dr Salerno. Did you refuse antegrade or retrograde cardioplegia?

Dr Scorsin. In this protocol, no. It was always continuous retrograde or antegrade cardioplegia.

Dr Uwe Mehlhorn (Cologne, Germany). I have 2 questions. First, did you always achieve complete cardiac arrest with your initial dose of esmolol? Second, what about your reperfusion times on pump? As you know, esmolol has a half-life of about 7 to 9 minutes, and it needs quite a while to be metabolized. What inotropic doses did you need?

Dr Scorsin. Those are good questions. We did not achieve complete arrest of the heart but minimal myocardial contraction with esmolol. So we can see that it is a very depressed myocardium. In this study there is no difference in bypass time after clamping the aorta, but after that, we have been using bypass for all kinds of patients, and we observed that sometimes we need more time to stop the CPB because the heart remained depressed with esmolol. In those patients we infuse a little bit of dobutamine to stimulate $\beta$-adrenergic receptors, and we can quickly stop CPB.

Dr Sidney Levitsky (Boston, Mass). This is a very interesting article because investigators have toyed with $\beta$-blockers for a long period of time. One of the advantages of something like esmolol is that it decreases the myocardial oxygen consumption very rapidly. As you know, the secret is the first 6 seconds, when the heart, after aortic crossclamping, goes from aerobic to anaerobic metabolism. The other advantage I think you have with the $\beta$-blocker is that potassium increases the cytosolic calcium within the cell, and I do not know what happens when you use something like esmolol or a $\beta$-blocker.

As far as you know, has anyone measured cytosolic calcium during a $\beta$-blocker or continuous $\beta$-blocker type of myocardial protection? As you know, the only purpose of using potassium is really to stop the heart from wiggling. In the past we have used, with the Quest System, just potassium and whole blood. That works well on a continuous basis, but if you want to do mitral valve surgery and coronary surgery you are not going to be able to use continuous infusion, unless you want to have a bloody field. I 
wonder whether this method will work as well under those circumstances.

I am sure you have done it, and you will probably have the answer, but it is very clever, and for aortic valve replacements with short crossclamp times, I think this might be a very valid method.

Dr Scorsin. As to the first question, I have no idea exactly. Nobody knows exactly how $\beta$-blockers work, but I am sure that calcium is one of the main issues involved in oxygen consumption.

About how to perfuse the heart, obviously it seems that the antegrade way is better. However, in these patients there were no coronary lesions. For patients undergoing coronary bypass, we must perfuse in a retrograde manner, and from time to time, as Dr Salerno said, it is better to give 2 or 3 minutes of antegrade perfusion.

Dr Frank W. Sellke (Boston, Mass). Your NO data are a little confusing to me. You are saying that esmolol increases endothelial preservation, yet NO release with esmolol is less. NO release is a very poor indicator of endothelial function, but if you were to use it, I would think that you would make the opposite conclusion.

Dr Scorsin. I will try to explain it better. The only difference that we could draw from the present study is that what induced NO is the direction of flow and of shear stress. Endothelial cells are aligned according to the direction of flow. When you change the direction of flow or when you change pressure or even oxygen content, you can stimulate endothelial cells to produce NO. That was the difference we saw between the antegrade group and the retrograde group.

Dr Sellke. Maintaining NO production is not necessarily-.

Dr Scorsin. It is a bad or a good thing? Nobody knows.

Dr Sellke. Well, it is debatable. There is some evidence that NO can help myocardial protection, but I do not think you should be using it as an indicator of endothelial dysfunction or injury. Your title says preserving myocardial metabolism and endothelial function. That is why I ask.

Dr Scorsin. Yes, because if NO is produced, maybe it is by inducible NO synthase.

Dr Sellke. Well, this is pretty early. I do not think so.

Dr Spotnitz. Let's stop right here. You gentlemen can discuss this privately. Dr Lazar or Dr Buckberg, do you have any comments?
Dr Gerald D. Buckberg (Los Angeles, Calif). Well, I am not sure what the NO data mean, but it is an interesting observation. Conceivably what you are seeing is that with retrograde flow that is continuous, you are really perfusing the same area all the time. Normally the heart contracts and relaxes, and that gives a distribution of flow, and maybe what you are seeing with the esmolol is that a small amount of contraction is providing flow to adjacent muscle, and you are seeing a more normal endothelial perfusion with that. Maybe the high NO might reflect the fact you have uneven flow, but it is recoverable. When you get back to normal perfusion you are seeing NO being produced to restore the endothelium. That might be one explanation for what you are seeing. The results were the same.

The other thing is that you are kind of looking at one thing or another, potassium or calcium blockage, and I think protection is not just one thing or the other. I think you have to combine many things. As Dr Salerno says, not only do you have to look at the way you are giving it, but you have to deal with many things when you are doing it. Therefore, you add many other parts to the cardioplegic solution. I do not think any method of protection with a single agent is going to be as good as a combination of things. As we learn more about the combination, I think our cardioplegic solutions will get better at protecting different areas.

Dr Bradley S. Allen (Oak Lawn, Ill). Let's talk a little bit about a different scenario and see what you think. Is it possible that the potassium is perfusing areas of the heart that because the NO is high the esmolol is not getting to? In other words, maybe it is getting to the subendocardium, and the NO is good; it is allowing the potassium to perfuse other areas, and that is why your oxygen content is a little higher because you are perfusing areas that otherwise would not be perfused.

I am curious when you talk about whether it is good or bad. Did you measure pressures in the cardioplegic solution? If the NO was good, then I would expect the pressure to be lower, and if the NO was bad and causing vascular endothelial damage, I expect those vessels to be edematous and not working. Therefore, the perfusion pressure, especially with antegrade cardioplegia, would be higher. Could you comment?

Dr Scorsin. These data are very difficult to understand. We opened the door, and therefore now we must understand what it means and follow with other studies. 